\title{
Implications of physicians and nurses' professional satisfaction on patient care
}

\author{
Wilson Kipkirui Aruasa, Linus Kipkorir Chirchir, Stanley Kulei Chebon \\ Moi Teaching and Referral Hospital, Kenya
}

\begin{tabular}{l}
\hline Article Info \\
\hline Article history: \\
Received Jun 9, 2019 \\
Revised Jul 20, 2019 \\
Accepted Aug 21, 2019 \\
\hline
\end{tabular}

\section{Keywords:}

Hospital

Nurses

Patient care

Physicians

Professional satisfaction

\begin{abstract}
The patient outcomes of a health organization depend on the knowledge, skills and motivation of its individual employees. Therefore, it is important for health care employers to motivate their workers in order to meet the desired outcomes. It is widely acknowledged that health workers who are motivated facilitate the desired patient outcomes. This illustrates how the levels of physicians' and nurses' professional satisfaction influences the health care outcomes for patients based on a study of the Moi Teaching and Referral Hospital (MTRH). Descriptive quantitative research design was used. Data was collected using a structured questionnaire issued to a stratified group of 82 Physicians and 220 Nurses. All the completed questionnaires were entered into IBM SPSS 21.0 statistical software and data analysed for descriptive statistics. The results were presented in tables and figures. The study was powered to $95 \%$ confidence interval. With regards to effects of general practitioners' and nurses' work satisfaction on patient services, the study revealed that work associated with the respondents' position allows contributions to be made to the hospital, the profession and to own sense of achievement. Furthermore, the study findings showed that praise received for work well done translates to improved job productivity and that the medicine/nursing practice allows autonomous professional decisions to be made which in turn promotes high levels of clinical competence. Based on these findings, the study concludes that health care practitioners' work satisfaction has implications on patient care.
\end{abstract}

Copyright $@ 2019$ Institute of Advanced Engineering and Science. All rights reserved.

\section{Corresponding Author:}

Dr. Wilson K. Aruasa,

Chief Executive Officer,

Moi Teaching and Referral Hospital,

P. O. Box 3-30100, Eldoret, Kenya.

E-mail: ceo@mtrh.go.ke

\section{INTRODUCTION}

The healthcare system in Kenya is technically structured from the most basic/primary healthcare facilities to the most specialized/national facilities, commonly referred to as Six Kenya Essential Package of Health (KEPH) levels. According to the National Health Sector Strategic Plan III 2012-2017 and Kenya Health Bill [1], these levels are: Level 1 (Community Health Services), Level 2 (Dispensary/Clinic), Level 3 (Health Centre), Level 4 (Primary Hospital), Level 5 (Secondary Hospital) and Level 6 (Tertiary Hospital). Moi Teaching and Referral Hospital (MTRH), along with both Kenyatta National Hospital (KNH) and Aga Khan University Hospital (AKUH), are the only Level 6 Hospitals in Kenya.

MTRH was established in 1917 as a cottage facility with in-patient capacity of 60 to provide health care to Africans. The current status of National Teaching and Referral Hospital was established by State Corporations Act (Cap.446) under Legal Notice No. 78 (12 th June, 1998). The core mandates for MTRH are: To take in cases on referral from other facilities in or outside the country for specialized services; to offer 
resources for medical training for the Moi University and for research either directly or through other co-facilities; to offer resources for training of nurses and other practitioners, and to contribute to Kenya's national health strategizing.

MTRH has a staff population of 3092 permanent and pensionable and 600 on contract. Physicians (doctors) are 338 (comprising 32 medical officers or general practitioners, 36 registrars [postgraduate trainees] and 270 specialists). Nurses are 901 (151 are specialized nurses, the rest being general nurses either with bachelor's degree or national diploma in nursing). The two cadres form the bulk of health workers geared towards delivery of MTRH's mission.

Satisfaction in the exercise of one's profession has its origins in the motivation-to-work two-factor theory of Herzberg [2]. Job satisfaction is the distinction of what one hopes for in relation to their work and the real outcomes in the workplace. It is a critical determiner of how workers gauge their work, how they fulfil work requirements, or even neglect their roles [3]. In present-day economy, remuneration and one's contentment with their nursing job portray the health care segment as a great place to serve others while cultivating personal growth. Job satisfaction is a vital aspect of the labour everywhere. Its absence both prevents the effectiveness of services and cause other ramifications like exhaustion [4]. Currently, practitioners who are abandoning their jobs is on the rise, due to different reasons [5].

Since the degree of work satisfaction shapes performance and the nature of care provided, it is crucial that facilities evaluate these views among workers. Most writings report a substantial link in health facilities between labourers and the patient's satisfaction levels [6]. The nursing career exposes one to various environments, to different health care services and to get fair remunerations. Many writers have evaluated the level of work satisfaction [7-8]. They have shown that acceptable pay, better job prospects and exciting work contribute to elevated job pleasure among nurses. Moreover, these workers are contented with the idea that they are assisting many other people. One of the published research about nurses' job satisfaction points to the absence of scholarly attention on commitment and work satisfaction in public facilities contexts [9].

\section{Implications of physicians' and nurses' professional satisfaction on patient care}

Needleman, Buerhaus, Mattke, Stewart and Zelevinsky [10] have demonstrated that a higher share of time of nursing services given by registered nurses daily is linked to better services for in-patients. In the United States, some states have legislated the least facility patient-nurse distribution [11]. In Aiken et al.'s Cross-sectional survey carried out in the state of California, facilities with high patient-nurse distribution had surgical care seekers receive higher risk-adjusted 30-day mortality and failure-to-rescue-rates, and nurses tended to experience exhaustion and job disaffection. Job displeasure among such nurses was four times higher than the mean for all US employees, and a fifth of facility-based nurses expressed desire to quit their positions soon.

Despite the above findings, the influential Audit Commission in England has concluded that there is no proof that more friendly patient-nurse distributions lead to enhanced patient services [11]. This may be due to relative inaccessibility of direct evidence linking nurse staffing ratios to hospital mortalities. Many writings have linked high number of registered nurses with reduced hospital deaths, albeit as a by-result of assessments targeting explicitly other features of facilities like tenure, teaching status or anaesthesiologist directors [12-14].

Practitioners in emergency sections often struggle in workplaces marked by reduced provision of, limited reach to and low stability of essential resources. Critical resource shortfalls can direly reduce the general pleasure in one's work. Physician work contentment incorporates many work-related job factors (dependent variables), like the general affection for the career, workplace associations, facility regulations and processes, pay, and work culture. For emergency workers, this is greatly impacted by the general demeanour of the workplace (independent variables). Provision of necessary aids, adequacy of these aids, and material stability shape their job contentment levels. Control variables to doctor job satisfaction include workflow and patient features, Institutional Characteristics (e.g. overcrowding) and physician characteristics (e.g. many works have shown that female workers are more contented with their work than their male colleagues) [15].

Rondeau, Francescutti and Zanardelli [15], in their study, report that reductions in resource access and availability affects physician job affection. Resource-based aspects that greatly lead to emergency workers' work contentment include their reach to of emergency department practitioners, provision of beds and hospital equipment, and steadiness of fiscal resources. Aiken et al. analysed surveys from 43,000 nurses from over 700 facilities in US, England, Canada, Germany and Scotland from 1998-99 [16]. Nurses in regions with uniquely variant health care structures posted the same weaknesses in their work scenarios and the quality of in-patient services. While the proficiency of and relationship of nurses and physicians seem acceptable, major concerns in job design and labour control threaten service delivery. Dealing with these

Implications of physicians and nurses' professional satisfaction on patient care (Wilson Kipkirui Aruasa) 
concerns, which call for administrative solutions, is critical to safeguarding patient safety and services with unfailing quality.

Further, in the United States, a correlation has been found between facility nurse recruitment and patient mortality, nurse exhaustion and work displeasure [17]. The study deduced that in facilities with elevated patient-nurse proportions, surgical cases tend to receive increased risk-adjusted 30-day mortality and failure-to-rescue levels, and nurses tended to suffer exhaustion and job displeasure. Low satisfaction among nurses and physicians leads to low morale at work and hence poor care of patients and poor patient outcomes.

\section{Statement of the problem}

Health care service quality is influenced by numerous aspects that include people, structures and equipment. Of these, workers constitute a critical element in the provision of care services. Health systems can never operate efficiently in the dearth of adequate trained, enthused and aided caregivers. The existence of highly trained and driven caregivers is a vital component of health system efficiency. Work satisfaction is equally essential to growing employee morale and effectiveness as it engenders enhanced output and increased patients' happiness as a result of good patient care. Nevertheless, job displeasure can lead to exhaustion and resignation which further cripple services in facilities.

There are few studies that have looked into factors affecting physicians and nurses' professional satisfaction in Kenya in general, and in MTRH in particular. On its part, MTRH [18-19] has undertaken two surveys to explore the overall staff satisfaction, but none of these surveys have been specific to physicians and nurses. These two surveys were conducted largely for Government of Kenya Performance Contracts requirements and did not have any particular theoretical construct/model utilized. From the surveys, employee satisfaction has stayed mostly constant, which in 2014 was 58\% and in 2015 was $55 \%$. These outcomes were despite of general improvements in staff basic salaries and other allowances. Therefore, it was necessary to explore how doctors and nurses' pleasure in their work influence patient service outcomes drawing proof from a major hospital such as the MTRH.

\section{RESEARCH METHOD}

The research design for this investigation was a descriptive cross-sectional survey. The study target subjects included doctors and nurses working at MTRH. There were 338 physicians (32 medical Officers, 36 registrars and 270 specialists/subspecialists). Nurses were 901 (151 specialised nurses and 750 non-specialised). The sampling frame that was used in the study was the full list of physicians and nurses employed at MTRH. The sampling frame followed the MTRH straight numerical system of personnel staff numbers. The inclusion criteria were: Qualified physicians and nurses on permanent and pensionable terms, and registered and licensed physicians and nurses with relevant professional regulatory entity. The exclusion criteria were: doctors and nurses on contract basis, and those who are currently on interdiction or suspension.

The respondents were stratified into Physicians and Nurses. Every 5th doctor in the list was interviewed, so long as the next interviewee was from a different department. If the 5th doctor was not from a different department as the immediate predecessor, the 6th was taken and so on. Every 10th Nurse in the list was interviewed, so long as the next interviewee was from a different department. This sampling procedure was based on the calculated sample size, the number of research assistants needed to cover this sample size and the need for the sample to be representative of the population. The sample size for physicians and nurses was calculated using Taro Yamane's formula [20]. By using Yamane's formula of sample size with an error limit of 5\% and with a confidence coefficient of $95 \%$, the calculation from a target population of 1239 physicians and nurses in MTRH arrived at a sample size of 302.

Field data was gathered using a questionnaire by the principal investigator, assisted by 5 research assistants who were hired and trained. Empirical validation of the study on factors affecting Physicians' was conducted using a questionnaire administered to 82 physicians and 220 nurses. All the data collected were entered into the statistical package and data cleaned for missing values and data entry errors. Data management was done using International Business Machines Statistical Package for the Social Science (IBM SPSS), version 21.0. Quantitative data were analysed to generate descriptive statistics which included frequencies, percentages and means. The study was powered to $95 \%$ confidence interval. Interpretation of the statistical outputs was done and discussed in the description of findings.

\section{RESULTS AND DISCUSSIONS}

The study sought to find out the repercussions of doctors and nurses' work satisfaction on patient care. The findings of the study revealed that work associated with the respondents' position allowed contributions to be made to the facility, the work and to own sense of accomplishment. Furthermore, 
the study findings indicated that adequate praise received for work well done from the hospital management and peers translated into improved job productivity and consequently improved patient care. The study also revealed that medicine/nursing practice allowed autonomous professional decisions to be made and promoted high levels of clinical competence which translates to quality patient care.

\subsection{Achievement of set targets}

About $69.5 \%$ of the respondents indicated that work associated with the position held allowed contributions to be made to the hospital whereas $69.5 \%$ indicated that it allowed contributions to be made to their profession as shown in Table 1 . A further $72.5 \%$ of the respondents indicated that the work held allowed contributions to be made to own sense of achievement as shown in Table 1. These outcomes were as depicted in Table 1.

Table 1. Achievement of set targets

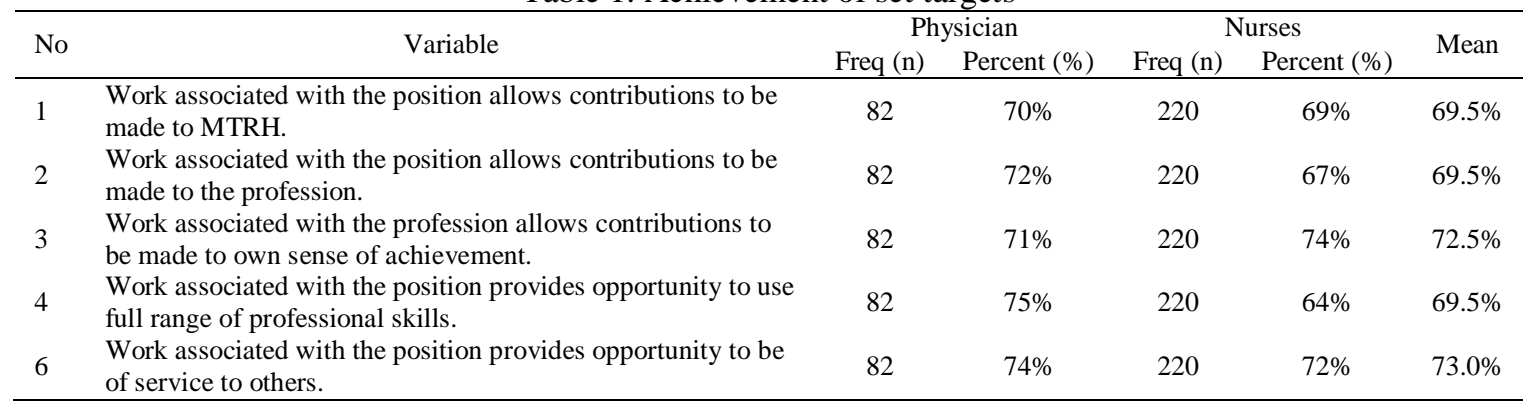

\subsection{Communication}

Communication was measured in the study with regards to supervisor and employee on accomplishment of tasks given. The study findings showed that sufficient praise received for work well executed from Hospital Management and colleagues translates to improved job productivity and consequently improved patient care. The study also revealed that medicine/nursing practice allowed autonomous professional decisions to be made and promoted high levels of clinical competence which translates to quality patient care. Sixty-four percent of the respondents indicated that adequate praise is received for work well done from peers whereas $61.5 \%$ indicated that adequate praise is received for work well done from the hospital management, it can be seen in Table 2. Another $62.0 \%$ indicated that adequate praise is received for work well done from medical/nursing administration as shown in Table 2 . These outcomes were as depicted in Table 2.

Table 2. Communication

\begin{tabular}{|c|c|c|c|c|c|c|}
\hline \multirow{2}{*}{ No } & \multirow{2}{*}{ Impacts } & \multicolumn{2}{|c|}{ Physician } & \multicolumn{2}{|c|}{ Nurses } & \multirow{2}{*}{ Mean } \\
\hline & & Freq $(n)$ & Percent $(\%)$ & Freq $(n)$ & Percent $(\%)$ & \\
\hline 1 & Adequate praise received for work well done from peers. & 82 & $67 \%$ & 220 & $61 \%$ & $64.0 \%$ \\
\hline 2 & $\begin{array}{l}\text { Adequate praise received for work well done from the } \\
\text { Hospital Management. }\end{array}$ & 82 & $68 \%$ & 220 & $55 \%$ & $61.5 \%$ \\
\hline 3 & $\begin{array}{l}\text { Adequate praise received for work well done from } \\
\text { Medical/Nursing Administration. }\end{array}$ & 82 & $72 \%$ & 220 & $52 \%$ & $62.0 \%$ \\
\hline
\end{tabular}

\subsection{Autonomy}

In this study, physicians and nurses' autonomy was measured using the ability to make autonomous professional decisions and accountability for any decisions made and implications to patient care. About $66.5 \%$ of the respondents indicated that medicine/nursing practice allowed autonomous professional decisions to be made whereas $66.0 \%$ indicated that medical/nursing practice allowed one to be fully accountable for decisions made as depicted in Table 3 . The findings were as presented in Table 3.

Table 3. Autonomy

\begin{tabular}{|c|c|c|c|c|c|c|}
\hline \multirow{2}{*}{ No } & \multirow{2}{*}{ Variable } & \multicolumn{2}{|c|}{ Physician } & \multicolumn{2}{|c|}{ Nurses } & \multirow{2}{*}{ Mean } \\
\hline & & Freq $(n)$ & Percent $(\%)$ & Freq $(n)$ & Percent $(\%)$ & \\
\hline 1 & $\begin{array}{l}\text { Medicine/Nursing practice allows autonomous professional } \\
\text { decisions to be made. }\end{array}$ & 82 & $68 \%$ & 220 & $65 \%$ & $66.5 \%$ \\
\hline
\end{tabular}

Implications of physicians and nurses' professional satisfaction on patient care (Wilson Kipkirui Aruasa) 


\subsection{Career advancement and research}

In this study, career advancement and research were measured using participation in research and training to promote high levels of competence because this has a direct correlation to improved patient care. Exactly $70.0 \%$ indicated that medical/nursing environment provided time to engage in research whereas $71.0 \%$ indicated that the medical/nursing environment promoted a high level of clinical competence and this had implications on patient care as shown in Table 4. The results for this item were as indicated in Table 4.

Table 4. Career advancement and research

\begin{tabular}{llccrr}
\hline No & \multicolumn{1}{c}{ Variable } & \multicolumn{2}{c}{ Physician } & \multicolumn{2}{c}{ Nurses } \\
Percent (\%) & Mean \\
\hline 1 & $\begin{array}{l}\text { Medical/Nursing environment supports participation in } \\
\text { research. }\end{array}$ & 82 & $76 \%$ & 220 & $64 \%$ \\
2 & $\begin{array}{l}\text { Medical/Nursing environment promotes a high level of } \\
\text { clinical competence. }\end{array}$ & 82 & $73 \%$ & 220 & $69 \%$ \\
\hline
\end{tabular}

\subsection{Chi-square test of association}

Chi-square test was deployed to explore the effect of nurses and physicians' professional satisfaction on patient care. With respect to achievement of targets in MTRH, the variables were found to be significant $(\mathrm{p}<0.05)$ in influencing patient care outcomes, it can be seen in Table 5.

Table 5. Chi-square test for achievement of set targets

\begin{tabular}{|c|c|c|c|c|}
\hline No & Variable & Chi-square Values & $\mathrm{df}$ & p-values $(<0.05)$ \\
\hline 1 & $\begin{array}{l}\text { Work associated with the position allows contributions to be made to } \\
\text { MTRH }\end{array}$ & 27.971 & 12 & 0.006 \\
\hline 2 & $\begin{array}{l}\text { Work associated with the position allows contributions to be made to } \\
\text { the profession }\end{array}$ & 21.111 & 12 & 0.049 \\
\hline 3 & $\begin{array}{l}\text { Work associated with the profession allows contributions to be made } \\
\text { to own sense of achievement }\end{array}$ & 35.636 & 12 & 0.000 \\
\hline 4 & $\begin{array}{l}\text { Work associated with the position provides opportunity to be of } \\
\text { service to others. }\end{array}$ & 32.321 & 12 & 0.001 \\
\hline
\end{tabular}

The factors under communication were also found to be significant $(\mathrm{p}<0.05)$ in influencing patient care outcomes as shown in Table 6.

Table 6. Chi-square test for communication

\begin{tabular}{llccc}
\hline No & Variable & Chi-square Values & df & p-values $(<0.05)$ \\
\hline 1 & Adequate praise received for work well done from peers & 21.483 & 12 & 0.044 \\
2 & Adequate praise received for work well done from MTRH & 34.313 & 15 & 0.003 \\
\hline
\end{tabular}

Three factors were found to be significant $(\mathrm{p}<0.05)$ in influencing patient care outcomes as shown in Table 7.

Table 7. Chi-square test for autonomy

\begin{tabular}{|c|c|c|c|c|}
\hline No & Variable & Chi-square Values & df & p-values $(<0.05)$ \\
\hline 1 & $\begin{array}{l}\text { Medicine/Nursing practice allows autonomous professional decisions to be } \\
\text { made. }\end{array}$ & 62.867 & 12 & 0.000 \\
\hline 2 & $\begin{array}{l}\text { Medical/Nursing environment allows full accountability for those decisions } \\
\text { made. }\end{array}$ & 34.091 & 12 & 0.001 \\
\hline 3 & $\begin{array}{l}\text { Medical/Nursing environment promotes a high level of clinical } \\
\text { competence. }\end{array}$ & 50.668 & 12 & 0.000 \\
\hline
\end{tabular}

The study revealed that there is a significant association between, on the one hand, contributions made by physicians and nurses to the hospital, profession and own sense of achievement and, on the other hand, improved patient care $(\mathrm{p}=0.006, \mathrm{p}=0.049, \mathrm{p}=0.000)$. Herzberg [21] premises that most individuals desire to do a good job. As such, it is the job of management to find and place employees in positions that 
utilize their talents and skills. Clear and achievable aims and ideals for each office should be defined. Employees should also get frequent feedback on their performance. Kumar and Singh [22] opine that achievement of work motivation positively and significantly relates to skill variety and task variety. Achievement is correlated with feedback from self. Engaging workers in decision-making or assigning them special designations or titles, together with constant output rewards, enables them to apprehend the importance of accomplishment. When accomplishment desires are fused with affiliation desires, the worker may become an efficient administrator or team head and can assist co-workers cultivate their desires for accomplishment.

Furthermore, a significant association was found between autonomy in medicine and nursing practice and patient care $(\mathrm{p}=0.000)$. In a survey by Stewart et al., nurses described freedom as their capacity to achieve their patient care aims promptly by deploying all gathered expertise, talents, practices and know-how to comprehend the problem and solutions for a care-seeker and to contribute to a strategy for recovery [23]. This contribution could entail evaluation of patient desires and circumstances, the efficient relay of information on the concerns and issues during care, and the analysis and harmonisation of the materials of the multidisciplinary group.

Praise received from peers and MTRH administration for work well done was found to significantly impact on patient care $(\mathrm{p}=0.044, \mathrm{p}=0.003)$. Work well done here means the patient is healed, happy and discharged as the final results of physicians and nurses' professional work. The practice of high-level clinical competence in medicine and nursing has a significant impact on patient care $(\mathrm{p}=0.000)$. In fact, Sengin posits that the materialization of career mobility and promotional prospects are crucial in lowering occupational strain among workers [24]. Medicine is a dynamic profession, meaning physicians and nurses have to keep upgrading their competences in order to meet the changing demands of their profession. Batista, Vieira, Cardoso and Carvalho have found that among the five motivational factors on the current work of the nurses surveyed, listed in order of priority, are: To love what you do, good relationship multidisciplinary, the possibility of professional growth, the power of problem solving linked to commitment population, working conditions, remuneration standing in seventh place [25]. By upgrading their skills, nurses increase their autonomy, salaries and recognition.

\section{CONCLUSION}

Doctors and nurses' work satisfaction have implications on patient services. This is because the contributions made by physicians and nurses and their respective professional bodies are important in improving patient care. Based on this fact, it is recommended that hospitals should strengthen their organizational structure to facilitate patient care by ensuring that physicians and nurses have a voice in issues that have implications to patient care in the healthcare environments. Moreover, they must avail health promoting organizational support practices, including work autonomy and clarity of roles and responsibilities (job descriptions) to improve on patient care outcomes.

\section{REFERENCES}

[1] Government of Kenya. National Health Sector Strategic Plan III 2012-2017 and Kenya Health Bill (2014). Nairobi: Government Printers, 2014.

[2] Herzberg, F.M. The Motivation to Work. New York: John Wiley \& Sons, 1959.

[3] Zahaj, M.; Saliaj, A.; Metani, L.; Nika, S.; Alushi, E. "Factors Related To Job Satisfaction Among Nurses," European Scientific Journal, vol.2, no.5, pp.100-110, 2016.

[4] Mrayyan, M.T. "Nurse job satisfaction and retention: comparing public to private hospitals in Jordan," Journal of Nursing Management, vol.13, no.1, pp.40-50, 2005.

[5] Raddaha, A.H.; Alasad, J.; Albikawi, Z.F.; Batarseh, K.S.; Realat, E.A.; Saleh, A.A.; Froelicher, E.S. "Jordanian nurses' job satisfaction and intention to quit," Leadership in Health Services, vol.25, no.3, pp.216-231, 2012.

[6] Knoop, R. "Relationships among job involvement, job satisfaction, and organizational commitment for nurses," The Journal of Psychology, vol.129, no.6, pp.643-649, 2010.

[7] Lorber, M.; Savič, B.S. "Job Satisfaction of Nurses and Identifying Factors of Job Satisfaction in Slovenian Hospitals," Croatian Medical Journal, vol.53, no.3, pp.263-270, 2012.

[8] Sultana, A.; Riaz, R.; Mehmood, F.; Khurshid, R. "Level of job satisfaction among nurses working in tertiary care hospitals of Rawalpindi," RMJ, vol.36, no.2, pp.150-154, 2011.

[9] Gabrani, A.; Hoxha, A.; Gabrani, J.; Petrela, E.; Zaimi, E.; Avdullari, E. "Perceived organizational commitment and job satisfaction among nurses in Albanian public hospitals: A cross-sectional study," International Journal of Healthcare Management, vol.9, no.2, 110-118, 2015.

[10] Needleman, J.; Buerhaus, P.; Mattke, S.; Stewart, M.; Zelevinsky, K. "Nurse-staffing levels and the quality of care in hospitals," New England Journal of Medicine, vol.346, no.22, pp.1715-1722, 2002. 
[11] [11] United Kingdom. “Audit Commission report on the NHS," International Journal of Healthcare Quality Assurance, vol.16, no.6, 2003. DOI: https://doi.org/10.1108/ijhcqa.2001.06214gab.015

[12] Hartz, A.J.; Krakauer, H.; Kuhn, E.M.; Young, M.; Jacobsen, S.J.; Greer Gay, L.M., Rimm, A.A. "Hospital characteristics and mortality rates," New England Journal of Medicine, vol.321, no.25, pp.1720-1725, 1989.

[13] Silber, J.H.; Kennedy, S.K.; Even-Shoshan, O.; Chen, W.; Koziol, L.F.; Showan, A.M.; Longnecker, D.E. "Anaesthesiologist direction and patient outcomes," The Journal of the American Society of Anesthesiologists, vol.93, no.1, pp.152-163, 2000.

[14] Shortell, S.M.; Hughes, E.F. "The effects of regulation, competition, and ownership on mortality rates among hospital inpatients," New England Journal of Medicine, vol.318, no.17, pp.1100-1107, 1988.

[15] Rondeau, K.V.; Francescutti, L.H.; Zanardelli, J.J. "Emergency Department Overcrowding: The Impact of Resource Scarcity on Physician Job Satisfaction,” Journal of Healthcare Management, vol.50, no.5, pp.327-340, 2005.

[16] Aiken, L.H.; Clarke, S.P.; Sloane, D.M.; Sochalski, J.; Silber, J.H. "Hospital nurse staffing and patient mortality, nurse burnout, and job dissatisfaction. JAMA, vol.288, no.16, pp.1987-1993, 2002. doi:10.1001/jama.288.16.1987

[17] Aiken, L.H.; Clarke, S.P.; Sloane, D.M.; Sochalski, J.A.; Busse, R.; Clarke, H.; . . Shamian, J. "Nurses' reports on hospital care in five countries," Health Aff (Milwood), vol.20, no.3, pp.43-53, 2001.

[18] Moi Teaching and Referral Hospital. Employee Satisfaction Survey. Eldoret: Moi Teaching and Referral Hospital, 2014.

[19] Moi Teaching and Referral Hospital. Employee Satisfaction Survey. Eldoret: Moi Teaching and Referral Hospital, 2015.

[20] Yamane, T. Statistics, An Introductory. $2^{\text {nd }}$ edn. New York: Harper and Row, 1967.

[21] Herzberg, F. Work and the nature of man. Cleveland: World Pub. Co, 1966.

[22] Kumar, N., Singh, V. "Job satisfaction and its correlates," International Journal of Research in Economics and Social sciences, vol. 1, no.2, pp.11-24, 2011.

[23] Stewart, J.; Stansfield, K.; Tapp, D. "Clinical nurses' understanding of autonomy: accomplishing patient goals through interdependent practice," Journal of Nursing Administration, vol.34, no.10, pp.443-450, 2004.

[24] Sengin, K.K. "Work-Related Attributes of RN Job Satisfaction in Acute Care Hospitals," Journal of Nursing Administration, vol.33, no.6, pp.317-320, 2003.

[25] Batista, A.A.; Vieira, M.J.; Cardoso, N.C.; Carvalho, G.R. "Motivation and dissatisfaction factors in the nurse's work," Revista da Escola de Enfermagem da USP, vol.39, no.1, pp.85-91, 2005.

\section{BIOGRAPHIES OF AUTHORS}

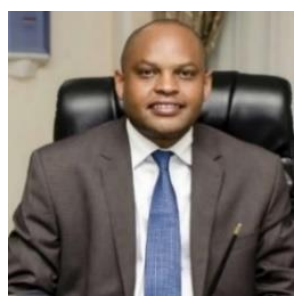

Dr. Wilson K. Aruasa, MBS, is a consultant Obstetrician and Gynaecologist and is currently serving as the Chief Executive Officer at the Moi Teaching and Referral Hospital, Eldoret, Kenya. His research interests are in transformational leadership, organizational performance, organizational diagnosis and development, healthcare financing/health economics, staff development (training, performance measurement, motivation/rewards and sanctions) among human resources for health and fertility management. Dr. Aruasa holds a Master of Medicine (MMed) in Obstetrics and Gynaecology from the University of Nairobi, Nairobi, Kenya and a Global Executive Master of Business Administration (GeMBA) from the United States International University - Africa, Nairobi, Kenya.

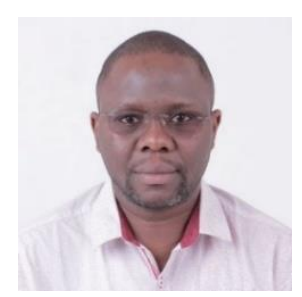

Linus K. Chirchir is a Senior Systems Administrator at the Moi Teaching and Referral Hospital, Eldoret, Kenya. His research interests are in health, leadership, management and information systems where he strives to advance knowledge in the use of information technology to improve quality of work life and organizational performance. He holds a Master of Information Systems from Kisii University, Kisii, Kenya and a Master of Business Administration from the United States International University - Africa, Nairobi, Kenya.

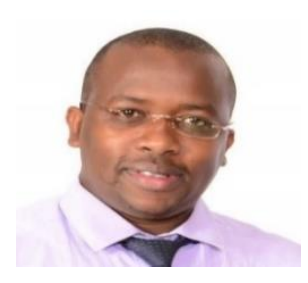

Stanley Kulei Chebon is the Manager, Planning, Monitoring and Evaluation at the Moi Teaching and Referral Hospital. He holds a Master of Public Health Degree from Moi University, Eldoret, Kenya and a Master of Business Administration - Health Leadership and Management from United States International University - Africa, Nairobi, Kenya. 